\title{
BMJ open Changing associations of episiotomy and anal sphincter injury across risk strata: results of a population-based register study in Finland 2004-2011
}

\author{
Sari Räisänen, ${ }^{1}$ Rufus Cartwright, ${ }^{2}$ Mika Gissler, ${ }^{3,4}$ Michael R Kramer, ${ }^{5}$ \\ Katariina Laine, ${ }^{6,7}$ Maija-Riitta Jouhki, ${ }^{3}$ Seppo Heinonen ${ }^{1,8}$
}

To cite: Räisänen $S$, Cartwright R, Gissler M, et al. Changing associations of episiotomy and anal sphincter injury across risk strata: results of a population-based register study in Finland 2004-2011. BMJ Open 2013;3:e003216. doi:10.1136/bmjopen-2013003216

- Prepublication history and additional material for this paper is available online. To view these files please visit the journal online (http://dx.doi.org/10.1136/ bmjopen-2013-003216).

Received 13 May 2013 Revised 19 June 2013 Accepted 10 July 2013

For numbered affiliations see end of article.

Correspondence to

Dr Sari Räisänen;

shraisan@student.uef.fi

\section{ABSTRACT}

Objectives: To evaluate the changing association between lateral episiotomy and obstetric anal sphincter injury (OASIS) for women with low and high baseline risk of OASIS.

Design: A population-based register study.

Setting: Data gathered from the Finnish Medical Birth Register for the years 2004-2011.

Participants: All women with spontaneous vaginal or vacuum-assisted singleton births in Finland ( $n=384638$ ).

Main outcome measure: OASIS incidence.

Results: During the study period, the incidence of OASIS increased from $1.3 \%$ to $1.7 \%$ in women with first vaginal births, including women admitted for first vaginal birth after a prior caesarean section and from $0.1 \%$ to $0.3 \%$ in women with at least one prior birth, whereas episiotomy rates declined from $56.7 \%$ to $45.5 \%$ and $10.1-5.3 \%$, respectively. At the study onset, when episiotomy was used more widely, it was negatively associated with OASIS in women with first vaginal births, but as episiotomy use declined it became positively associated with OASIS. Women with episiotomy were complicated by OASIS with clearly higher risk scores than women without episiotomy suggesting that episiotomy was clearly protective against OASIS. OASIS occurred with lower mean risk scores among women with and without episiotomy over time. However, OASIS incidences increased only among women with episiotomy, whereas it decreased or remained among women without episiotomy.

Conclusions: The cross-over effect between episiotomy and OASIS could be explained by increasing disparity in baseline OASIS risk between treated and untreated women, since episiotomy use declined most in women at low OASIS risk. Episiotomy rate can be safely reduced in low-risk women but interestingly along with the policy change the practice to cut the episiotomy became less protective among high-risk women.

\section{INTRODUCTION}

Obstetric anal sphincter injury (OASIS) is a serious complication of vaginal delivery with

\section{ARTICLE SUMMARY}

Article focus

- To re-evaluate the association between obstetric anal sphincter injury (OASIS) and lateral episiotomy, for women at varying baseline risk of OASIS based on number of prior vaginal births, mode of delivery (spontaneous vaginal or vacuum assisted) and birth weight.

- To assess whether increasing OASIS incidence was mostly attributable to secular changes in risk factors for OASIS, and whether there was measurable confounding by indication, with an association between use of episiotomy and baseline risk of OASIS.

Key messages

- During 2004-2011 total episiotomy rates declined, while OASIS incidences increased among both women with first vaginal births and women with prior vaginal births.

- An increasingly positive association between episiotomy and OASIS was observed, as episiotomy was used increasingly restrictively.

- The cross-over effect between episiotomy and OASIS could be explained by increasing disparity in baseline OASIS risk between treated and untreated women, since episiotomy use declined most in women at low OASIS risk.

- The observed statistical association between lateral episiotomy and OASIS was profoundly modified by episiotomy rate, serving here as a surrogate for unmeasured confounding by indication.

Strengths and limitations of this study

- The strength was that data source was a mandatory national database that covers the entire Finnish population.

- We were not able to include all known risk factors for OASIS in the models such as length of the second stage of labour, episiotomy indications and fetal distress.

up to two-thirds of women affected by it suffering from anal incontinence. ${ }^{1}$ Although there is an overall increase in the incidence 
of OASIS, there are substantial differences in incidence between countries, ranging from $0.2 \%$ to $4.0 \%$ in 2010 in Europe ${ }^{2}$ and from $3.5 \%$ to $5.9 \%$ in the $\mathrm{USA}^{3}{ }^{4}$ in the last decade. It is unclear whether such trends reflect differences in populations, in diagnosis and registration, or differences in management of delivery between and within countries. ${ }^{5} 6$ The association between episiotomy and OASIS remains a controversial source of debate. The available evidence from randomised controlled studies suggests that restrictive use of episiotomy leads to less need for suturing, better healing outcomes and reduced severe perineal trauma (RR $0.67,95 \%$ CI 0.49 to $0.91,7$ trials, $n=4404) .{ }^{7}$ However, further, large observational studies have suggested that although the midline type of episiotomy is associated with increased OASIS risk, ${ }^{8}$ the mediolateral episiotomy technique is associated with substantially decreased OASIS risk. ${ }^{9}$

Lateral episiotomy, the exclusive episiotomy technique practiced in Finland, is when an incision is made to the vaginal introitus 1 or $2 \mathrm{~cm}$ lateral to the midline and directed towards the ischial tuberosity. ${ }^{10}$ Our previous work demonstrated that lateral episiotomy was associated with a lower OASIS incidence in first births and a higher rate in second and subsequent births, ${ }^{11}$ but use of episiotomy had declined substantially over the decade to 2007 among both women with first vaginal births and multiparous women as the incidence of OASIS increased..$^{12}$ As the use of episiotomy has become even more restrictive, the aim of this retrospective case-control study was to re-evaluate the association between OASIS and lateral episiotomy, for women at varying baseline risk of OASIS based on number of prior vaginal births, mode of delivery (spontaneous vaginal or vacuum assisted) and birth weight. We wished to assess whether increasing OASIS incidence was mostly attributable to secular changes in risk factors for OASIS, and whether there was measurable confounding by indication, with an association between use of episiotomy and baseline risk of OASIS.

\section{MATERIALS AND METHODS}

\section{Data and population}

The data were gathered from the Finnish Medical Birth Register (MBR) that includes information on maternal and neonatal birth characteristics and perinatal outcomes during seven postnatal days for all births after the 22nd gestational week or weighing $500 \mathrm{~g}$ or more. The authorisation to utilise a sensitive health register data for the period from 2004 to 2011 was granted by THL National Institute for Health and Welfare, the current register keeper, according to national data protection legislation.

Incidence of OASIS is defined by the International Classification of Diseases (ICD-10) codes O70.2 (3rd degree) and O70.3 (4th degree), and has been captured in the MBR since 2004, as well as the Hospital Discharge Register (HDR). The two data sources were linked together using encrypted unique personal identification numbers. We used only anonymised data, and accordingly informed consent of the registered individuals was not needed. The HDR also provided information on other medical interventions and surgical procedures during pregnancy and birth. Women with a second or subsequent OASIS $(n=34)$ were excluded from analysis.

The study population included all women with singleton vaginal spontaneous or vacuum-assisted delivery ( $\mathrm{n}=384638$ ) during the study period from 2004 to 2011. The deliveries were categorised into two groups based on number of prior vaginal births; women with first vaginal births including women admitted for first vaginal birth after a prior caesarean section (CS), that is, first vaginal birth $(n=168081)$ and women with at least one prior vaginal birth $(\mathrm{n}=216557)$. The study period was grouped into four 2-year periods to compute the secular trends in OASIS incidences, episiotomy rates and risk profiles during the study period.

\section{Variables and definitions}

The degree of OASIS was classified according to standard definitions; a third-degree injury involves the external anal sphincter and a fourth-degree injury affects both the anal sphincter and the anorectal mucosa. ${ }^{13}$ Third-degree injuries and fourth-degree injuries were pooled for all the analyses. Mode of delivery was classified either vaginal spontaneous or vacuum-assisted; forceps and breech were excluded from the analytic dataset due to low number of cases. Breech, forceps and CS rates are presented as additional information. Gestational age was estimated based on data for the last menstrual period, unless there was a discrepancy of more than 7 or 14 days at the first-trimester or second-trimester ultrasound measurements, respectively. Smoking during pregnancy was self-reported and grouped as non-smoking, given up smoking during the first trimester and continued smoking after the first trimester.

\section{Statistical analyses}

To assess association of episiotomy and OASIS over time and risk group, we computed risk scores for OASIS based on OASIS incidences for all years pooled for subgroups of women, by number of prior vaginal births, mode of current delivery (vaginal spontaneous or vacuum assisted) and mode of prior delivery (CS or vaginal), separately for four birth weight strata $(<3000$, 3000-3499, 3500-3999 and $\geq 4000 \mathrm{~g}$ ). We calculated risk scores separately for women with first vaginal births, including women admitted for first vaginal birth after a prior caesarean section, and women with at least one prior vaginal birth. For both groups, women with the lowest OASIS incidence were assigned a risk score of 1.0 and those with higher risks had each risk factor multiplied by the relative increase in the OASIS incidences compared to this reference group. Thus, risk scores did not allow comparison between the two groups of women. Factors used in the risk scores (number of prior vaginal births, prior CS before first vaginal delivery, birth 
weight and mode of delivery) were chosen as recognised independent risk factors for OASIS from previous analyses of this register. We defined two risk strata (low and high) for OASIS during the entire study period separately for both groups of women, to assess possible changes in OASIS risk profiles over time based on receiver operator characteristic (ROC) curves (not shown). The best thresholds to maximise sensitivity and specificity were 1.85 (sensitivity $49 \%$ and specificity $72 \%$ ) in women with first vaginal births and 2.50 (sensitivity $50 \%$ and specificity $76 \%$ ) in women with at least one prior vaginal birth that were chosen as cut offs between low-risk and high-risk strata for both groups. Risk scores ranged from 1.0 to 4.9 in women with first vaginal birth and from 1.0 to 14 in women with at least one prior vaginal birth.
Statistical tests were performed separately for both groups of women with and without OASIS or with and without episiotomy. Statistical differences in categorical variables were evaluated by $\chi^{2}$ test and differences in continuous variables by Mann-Whitney U, Kruskal-Wallis, Student's $\mathrm{t}$ or analysis of variance (ANOVA) tests as appropriate. Logistic regression analyses were used to calculate OR of OASIS with 95\% CI adjusting for statistically significant independent and clinically important risk factors for OASIS $(p<0.1)$ including maternal age, gestational age, prior CS, birth weight, mode of delivery, episiotomy, epidural analgesia and maternal smoking. Information on length of active second stage of birth was missing in $83156(21.7 \%)$ cases and thus this variable was not included in analyses. The data were analyzed using Predictive Analytics SoftWare V.19.0.

Table 1 Demographics and delivery characteristics were compared between four 2-year time periods separately in singleton women with first vaginal birth including women admitted for first vaginal birth after a prior caesarean section ( $\mathrm{n}=168 \mathrm{081})$ and women with at least one prior vaginal birth $(n=216557)$ in 2004-2011 in Finland

\begin{tabular}{|c|c|c|c|c|c|c|}
\hline & 2004-2005 & 2006-2007 & 2008-2009 & 2010-2011 & ${ }^{*}$ p Value & $\begin{array}{l}\text { Pooled } \\
2004-2011\end{array}$ \\
\hline \multicolumn{7}{|l|}{ Women with first vaginal birth } \\
\hline Mean maternal age (SD) (year) & $27.2(5.2)$ & $27.4(5.1)$ & $27.5(5.1)$ & $27.7(5.2)$ & $\leq 0.001$ & $27.4(5.2)$ \\
\hline Mean gestational weeks (SD) & $39.9(1.7)$ & $39.9(1.7)$ & $40.0(1.7)$ & $40.0(1.7)$ & 0.08 & $40.0(1.7)$ \\
\hline Epidural analgesia (\%) & 67.6 & 59.7 & 69.9 & 71.3 & $\leq 0.001$ & 67.2 \\
\hline Episiotomy (\%) & 56.7 & 54.6 & 50.3 & 45.5 & $\leq 0.001$ & 51.7 \\
\hline OASIS (\%) & 1.3 & 1.5 & 1.5 & 1.7 & $\leq 0.001$ & 1.5 \\
\hline OASIS without episiotomy $(\%(n))$ & $1.3(227)$ & $1.2(226)$ & $1.0(212)$ & $1.1(247)$ & 0.04 & $1.1(912)$ \\
\hline OASIS with episiotomy $(\%(n))$ & $1.3(312)$ & $1.8(419)$ & $2.1(447)$ & $2.5(485)$ & $\leq 0.001$ & $1.9(1663)$ \\
\hline \multicolumn{7}{|c|}{ Mode of delivery (\%) } \\
\hline Vaginal spontaneous & 63.4 & 61.5 & 60.9 & 60.5 & $\leq 0.001$ & 61.6 \\
\hline Vacuum & 12.7 & 14.4 & 14.9 & 15.0 & & 14.3 \\
\hline Breech† & 0.6 & 0.6 & 0.6 & 0.8 & & 0.6 \\
\hline Forceps† & 0.1 & 0.1 & 0.1 & 0.1 & & 0.1 \\
\hline Caesarean section $†$ & 23.2 & 23.4 & 23.4 & 23.7 & & 23.4 \\
\hline Prior caesarean section (\%) & 8.3 & 8.4 & 8.6 & 9.0 & 0.001 & 8.6 \\
\hline Mean birth weight (SD) (g) & $3464.2(494.5)$ & $3443.4(495.7)$ & 3436.9 (492.1) & $3438.4(490.3)$ & $\leq 0.001$ & $3445.5(493.2)$ \\
\hline \multicolumn{7}{|c|}{ Women with at least one prior vaginal birth } \\
\hline Mean maternal age (SD) & $30.8(5.1)$ & $30.8(5.1)$ & $30.8(5.0)$ & $30.8(4.9)$ & 0.11 & $30.8(5.0)$ \\
\hline Mean gestational weeks (SD) & $39.9(1.6)$ & $39.9(1.5)$ & $39.9(1.5)$ & $39.9(1.5)$ & 0.17 & $39.9(1.5)$ \\
\hline Epidural analgesia (\%) & 22.8 & 19.1 & 23.9 & 25.4 & $\leq 0.001$ & 22.9 \\
\hline Episiotomy (\%) & 10.1 & 8.4 & 6.7 & 5.3 & $\leq 0.001$ & 7.6 \\
\hline OASIS (\%) & 0.2 & 0.2 & 0.2 & 0.3 & $\leq 0.001$ & 0.2 \\
\hline $\begin{array}{l}\text { OASIS without episiotomy } \\
(\%(n))\end{array}$ & $0.1(62)$ & $0.1(70)$ & $0.2(80)$ & $0.2(98)$ & 0.15 & $0.2(310)$ \\
\hline OASIS with episiotomy (\% (n)) & $0.3(17)$ & $1.2(53)$ & $1.2(46)$ & $2.1(61)$ & $\leq 0.001$ & $1.1(177)$ \\
\hline \multicolumn{7}{|c|}{ Mode of delivery (\%) } \\
\hline Vaginal spontaneous & 87.9 & 88.1 & 88.3 & 88.1 & $\leq 0.001$ & 88.1 \\
\hline Vacuum & 2.1 & 2.4 & 2.4 & 2.7 & & 2.4 \\
\hline Breech† & 0.5 & 0.5 & 0.6 & 0.6 & & 0.5 \\
\hline Forceps† & 0.0 & 0.0 & 0.0 & 0.0 & & 0.0 \\
\hline Caesarean section $†$ & 9.5 & 9.1 & 8.7 & 8.6 & & 8.9 \\
\hline Prior caesarean section (\%) & 5.6 & 5.7 & 5.6 & 5.6 & 0.90 & 5.6 \\
\hline Mean birth weight (SD) (g) & $3637.7(510.8)$ & $3625.2(500.9)$ & 3610.6 (499.3) & $3612.1(497.9)$ & $\leq 0.001$ & $3621.1(502.2)$ \\
\hline
\end{tabular}



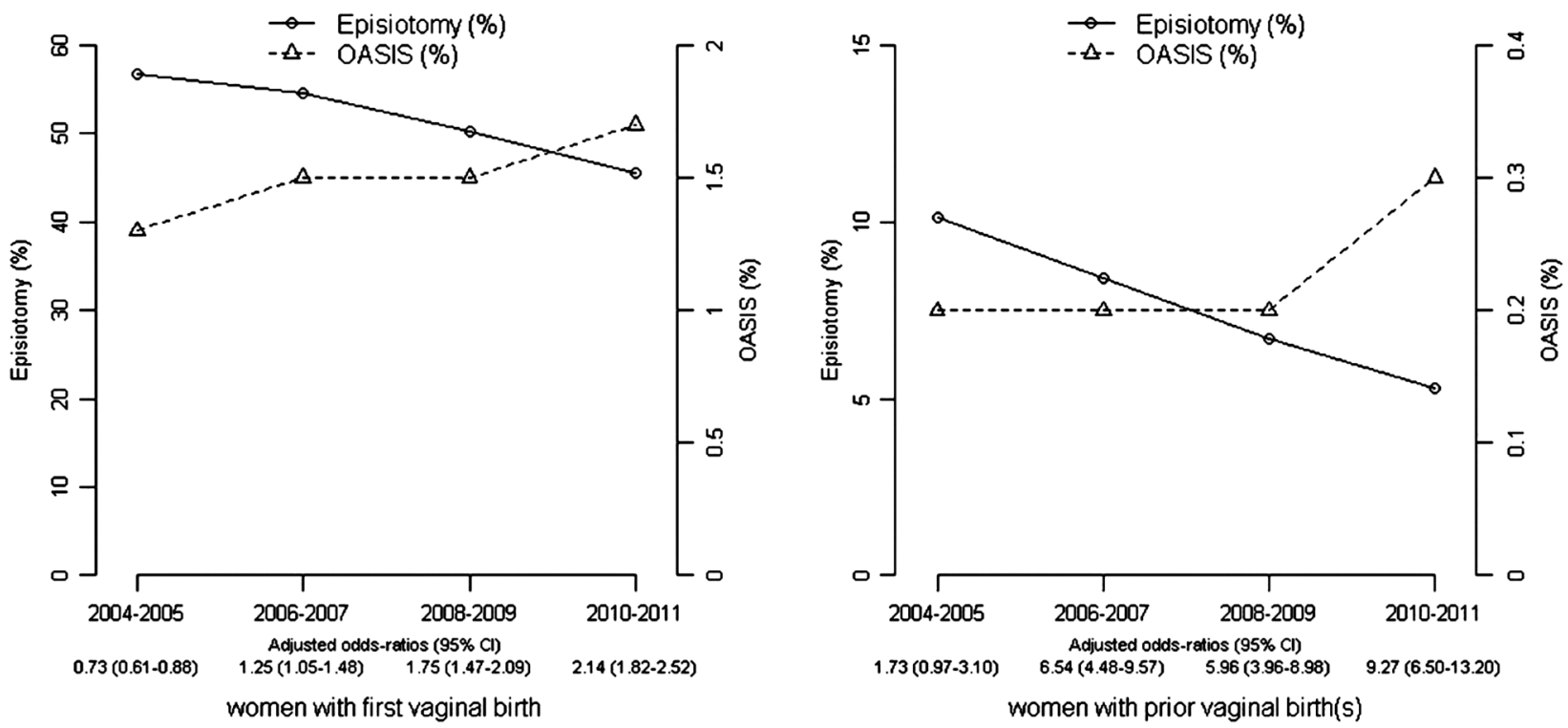

Figure 1 Changes in episiotomy rate and obstetric anal sphincter injury rate and their adjusted association, stratified by number of prior vaginal births 2004-2011.

\section{RESULTS}

For the women with first vaginal births, including women admitted for first vaginal birth after a prior caesarean section $(\mathrm{n}=168081)$, with singleton vaginal spontaneous or vacuum-assisted births, episiotomy rate decreased between 2004-2005 and 2010-2011 from $56.7 \%$ to $45.5 \%$ while OASIS incidences increased from $1.3 \%$ in $2004-2005$ to $1.7 \%$ in $2010-2011$ (table 1). For women with at least one prior vaginal birth $(\mathrm{n}=216557)$, episiotomy rate almost halved from $10.1 \%$ to $5.3 \%$ while OASIS incidences increased from $0.2 \%$ in $2004-2009$ to
$0.3 \%$ in 2010-2011. As episiotomy use became more restrictive, OASIS incidences increased. After adjustment episiotomy was positively associated with OASIS among both groups (figure 1). Furthermore, OASIS incidences decreased in women who gave birth without an episiotomy while increased in women with episiotomy among both groups of women (figure 2).

Secular trends of demographics and obstetric interventions were modest (table 1) with the exception of a slight increase in use of vacuum assistance (unadjusted OR (uOR) 1.24, 95\% CI 1.20 to 1.29 and uOR 1.28,
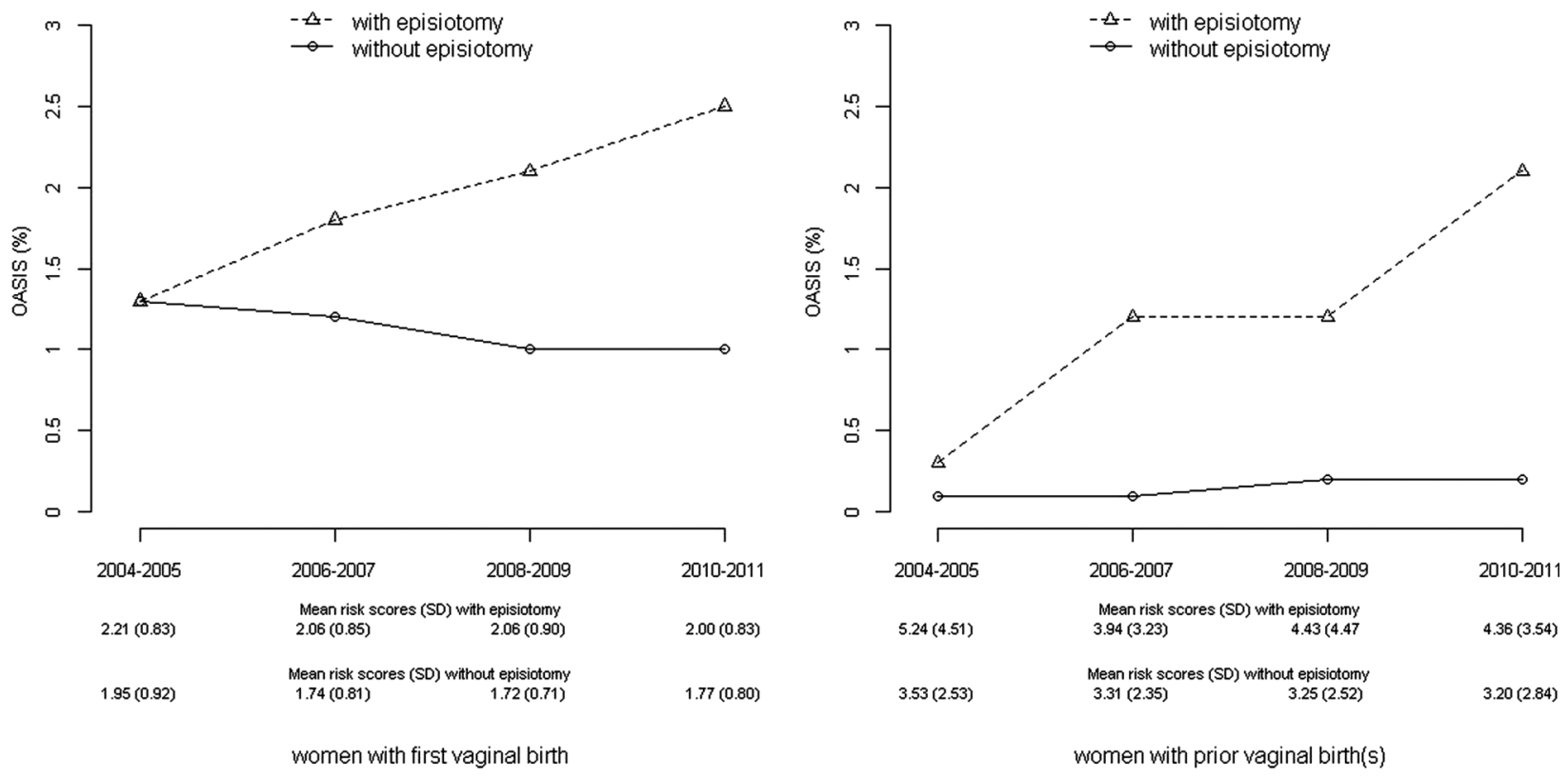

Figure 2 Obstetric anal sphincter injury incidences in women with and without episiotomy in women with first vaginal births including women admitted for first vaginal birth after a prior caesarean section and women with at least one prior vaginal birth women in 2004-2011. 
Table 2 Risk scores* of OASIS among women with first vaginal birth without and with a prior caesarean section (CS) and women with at least one prior vaginal birth according to birth weight groups in spontaneous vaginal and vacuum-assisted births

\begin{tabular}{|c|c|c|c|}
\hline $\begin{array}{l}\text { Characteristics according to birth } \\
\text { weight groups }\end{array}$ & $\begin{array}{l}\text { Women with first } \\
\text { vaginal birth } \\
\text { Risk scores }\end{array}$ & $\begin{array}{l}\text { Women with first vaginal } \\
\text { births after a prior CS } \\
\text { Risk scores }\end{array}$ & $\begin{array}{l}\text { Women with at least one } \\
\text { prior vaginal birth } \\
\text { Risk scores }\end{array}$ \\
\hline \multicolumn{4}{|l|}{$<3000 \mathrm{~g}$} \\
\hline Vaginal spontaneous & 1 & 1.3 & 1 \\
\hline Vacuum assisted & 1 & 3.7 & 3 \\
\hline \multicolumn{4}{|l|}{$3000-3499 \mathrm{~g}$} \\
\hline Vaginal spontaneous & 1 & 1.3 & 1 \\
\hline Vacuum assisted & 2.2 & 2.3 & 8 \\
\hline \multicolumn{4}{|l|}{$3500-3999 \mathrm{~g}$} \\
\hline Vaginal spontaneous & 1.5 & 2.3 & 2 \\
\hline Vacuum assisted & 2.8 & 2.8 & 10 \\
\hline \multicolumn{4}{|l|}{$\geq 4000 \mathrm{~g}$} \\
\hline Vaginal spontaneous & 2.5 & 3.9 & 4 \\
\hline Vacuum assisted & 3.2 & 4.9 & 14 \\
\hline
\end{tabular}

95\% CI 1.19 to 1.38 in 2010-2011 compared with 20042005 in women with first vaginal births and women with prior vaginal births, respectively, data not shown) and epidural analgesia (uOR 1.15, 95\% CI 1.12 to 1.18 and uOR $1.18,95 \%$ CI 1.15 to 1.22 , respectively in 20102011 compared with 2004-2005, data not shown). Furthermore, risk scores (table 2) among those women with first vaginal births (mean 1.60, range 1.00-4.90) were constant across the 8-year period, whereas the women with prior vaginal births showed a slight but statistically significant difference in risk profile across the 2-year time periods (mean 2.23 to 2.28 , range 1.00 to 14.00; table 3).

Episiotomy use declined both among women at low and high risk of OASIS in both groups but most among women at low risk (table 4). Use of episiotomy decreased significantly by $27 \%$ (uOR 0.58 , 95\% CI 0.56 to 0.60 ) and $9 \%$ (uOR $0.74,95 \%$ CI 0.70 to 0.79 ) among women with first vaginal births with low-risk and high-risk scores, respectively. Among women with prior vaginal births, episiotomy use decreased by $52 \%$ (uOR $0.45,95 \%$ CI 0.43 to 0.48 ) and $36 \%$ (uOR $0.60,95 \%$ CI 0.56 to 0.65 ) among women with low-risk and high-risk scores, respectively. Correspondingly, OASIS incidences increased most among women at low risk of OASIS among both groups but also among women with prior vaginal births at high risk of OASIS. The incidence of OASIS increased significantly by $63 \%$ (uOR 1.60, 95\% CI 1.37 to 1.88 ) in women with first vaginal delivery at low risk, but not in women with first vaginal births at high risk, and doubled in women with prior vaginal births at both low risk and high risk (uOR 2.24, 95\% CI 1.51 to 3.35 ) and (uOR $1.69,95 \%$ CI 1.17 to 2.45$)$, respectively. Furthermore, in both groups regardless of risk group OASIS incidences increased in women with episiotomy, whereas decreased or remained the same in women without episiotomy.
Table 3 shows the mean risk scores of OASIS, episiotomy and OASIS with and without episiotomy. The mean risk scores of women who underwent episiotomy increased over time and were significantly higher than in women without episiotomy. The mean risk scores of women affected by OASIS decreased during the study period among both groups. Further, women with episiotomy were complicated by OASIS with higher mean risk scores than women without episiotomy in both groups as an indication of a protective effect brought about by episiotomy.

\section{DISCUSSION}

During the study period in 2004-2011 total episiotomy rates declined, while OASIS incidences increased among both women with first vaginal births including women admitted for first vaginal birth after a prior caesarean section and women with at least one prior vaginal birth women. Paradoxically, we observed an increasingly positive association between episiotomy and OASIS, as episiotomy was used increasingly restrictively. Across a wide range of known risks for OASIS, we observed that the OASIS risk profile for the overall population was constant during the years studied, not explaining this increased OASIS incidence. However, episiotomy use declined sharply among women at low baseline risk, while conversely OASIS incidences increased among women with episiotomy while decreasing or remaining the same among women without episiotomy. Thus, the observed statistical association between lateral episiotomy and OASIS was profoundly modified by episiotomy rate, serving here as a surrogate for unmeasured confounding by indication. These results, in parallel with those from randomised trials, suggest that the episiotomy rate can be safely reduced in low-risk women, without any increase in OASIS rate. 
Table 3 Distribution of low and high baseline risk of obstetric anal sphincter injury (OASIS) and the mean risk scores of OASIS separately among women with first vaginal births including women admitted for first vaginal birth after a prior caesarean section and in women with at least one prior birth between four 2-year periods in 2004-2011

\begin{tabular}{|c|c|c|c|c|c|c|}
\hline & 2004-2005 & 2006-2007 & 2008-2009 & 2010-2011 & p Value & $\begin{array}{l}\text { Pooled } \\
2004-2011\end{array}$ \\
\hline Women with first vaginal birth & 40995 & 41664 & 42684 & 42738 & & 168081 \\
\hline \multicolumn{7}{|l|}{ Risk score range $1.0-4.9$} \\
\hline Mean risk scores among all nulliparous (SD) & $1.60(0.73)$ & $1.60(0.73)$ & $1.60(0.73)$ & $1.60(0.74)$ & $0.88^{*}$ & $1.60(0.73)$ \\
\hline Mean risk scores (SD) with OASIS $(n=2575) \dagger$ & $2.10(0.88)$ & $1.95(0.85)$ & $1.95(0.86)$ & $1.92(0.83)$ & $0.001^{\star \star}$ & $1.97(0.85)$ \\
\hline Mean risk scores (SD) without OASIS & $1.59(0.72)$ & $1.60(0.73)$ & $1.59(0.72)$ & $1.60(0.74)$ & 0.92 & $1.59(0.73)$ \\
\hline Mean risk scores (SD) with episiotomy & $1.72(0.78)$ & $1.75(0.79)$ & $1.78(0.80)$ & $1.82(0.81)$ & $\leq 0.001^{*}$ & $1.76(0.80)$ \\
\hline Mean risk scores (SD) without episiotomy & $1.43(0.62)$ & $1.42(0.62)$ & $1.41(0.59)$ & $1.43(0.62)$ & $\leq 0.001$ & $1.42(0.61)$ \\
\hline $\begin{array}{l}\text { Mean risk scores (SD) with OASIS }(n=1663) \\
\text { and with episiotomy } \ddagger\end{array}$ & $2.21(0.83)$ & $2.06(0.85)$ & $2.06(0.90)$ & $2.00(0.83)$ & $0.007^{\star \star}$ & $2.07(0.86)$ \\
\hline $\begin{array}{l}\text { Mean risk scores (SD) with OASIS }(n=912) \\
\text { and without episiotomy }\end{array}$ & $1.95(0.92)$ & $1.74(0.81)$ & $1.72(0.71)$ & $1.77(0.80)$ & $0.01^{\star *}$ & $1.80(0.82)$ \\
\hline $\begin{array}{l}\text { uOR }(95 \% \mathrm{Cl}) \text { of episiotomy associated } \\
\text { with OASIS }\end{array}$ & 1.05 (0.89 to 1.25$)$ & 1.55 (1.32 to 1.83$)$ & 2.10 (1.78 to 2.48$)$ & 2.39 (2.05 to 2.79$)$ & & \\
\hline $\begin{array}{l}\text { aOR }(95 \% \mathrm{CI}) \text { of episiotomy associated } \\
\text { with OASIS§ }\end{array}$ & 0.73 (0.61 to 0.88$)$ & 1.25 (1.05 to 1.48$)$ & 1.75 (1.47 to 2.09$)$ & 2.14 (1.82 to 2.52$)$ & & \\
\hline Women with at least one prior vaginal birth & 52274 & 53338 & 55180 & 55765 & & 216557 \\
\hline \multicolumn{7}{|l|}{ Risk score range $1.0-14.0$} \\
\hline Mean risk scores among all multiparous & $2.28(1.73)$ & $2.26(1.78)$ & $2.23(1.77)$ & $2.26(1.81)$ & $\leq 0.001^{*}$ & $2.26(1.78)$ \\
\hline Mean risk scores (SD) with OASIS $(n=487) \dagger$ & $3.90(3.11)$ & $3.59(2.77)$ & $3.68(3.40)$ & $3.65(3.17)$ & $0.46^{\star \star}$ & $3.68(3.11)$ \\
\hline Mean risk scores (SD) without OASIS & $2.28(1.73)$ & $2.26(1.78)$ & $2.23(1.77)$ & $2.26(1.81)$ & $\leq 0.001$ & $2.26(1.77)$ \\
\hline Mean risk scores (SD) with episiotomy $†$ & $3.14(2.90)$ & $3.33(3.19)$ & $3.55(3.36)$ & $3.85(3.64)$ & $\leq 0.001^{\star *}$ & $3.41(3.23)$ \\
\hline Mean risk scores (SD) without episiotomy & $2.18(1.52)$ & $2.16(1.55)$ & $2.14(1.56)$ & $2.17(1.62)$ & $\leq 0.001$ & $2.16(1.56)$ \\
\hline $\begin{array}{l}\text { Mean risk scores (SD) with OASIS }(n=177) \\
\text { and with episiotomy } \ddagger\end{array}$ & $5.24(4.51)$ & $3.94(3.23)$ & $4.43(4.47)$ & $4.36(3.54)$ & $0.67^{\star *}$ & $4.34(3.80)$ \\
\hline $\begin{array}{l}\text { Mean risk scores (SD) with OASIS }(n=310) \\
\text { and without episiotomy }\end{array}$ & $3.53(2.53)$ & $3.31(2.35)$ & $3.25(2.52)$ & $3.20(2.84)$ & $0.88^{\star \star}$ & $3.31(2.58)$ \\
\hline $\begin{array}{l}\text { uOR }(95 \% \mathrm{Cl}) \text { of episiotomy associated } \\
\text { with OASIS }\end{array}$ & 2.45 (1.43 to 4.20$)$ & 8.32 (5.82 to 11.91$)$ & 8.07 (5.61 to 11.61$)$ & $11.33(8.21$ to 15.63$)$ & & \\
\hline $\begin{array}{l}\text { aOR }(95 \% \mathrm{CI}) \text { of episiotomy associated } \\
\text { with OASIS§ }\end{array}$ & $1.73(0.97$ to 3.10$)$ & 6.54 (4.48 to 9.57$)$ & 5.96 (3.96 to 8.98$)$ & 9.27 (6.50 to 13.20$)$ & & \\
\hline
\end{tabular}

*Analysis of variance (ANOVA) or **Kruskal-Wallis tests.

†Differences between the groups were statistically significant $(p \leq 0.001)$ in each time period (Student's $t$-test).

fDifferences between the groups were statistically significant $(p \leq 0.001)$ among women with first vaginal birth in each time period and among women with at least one prior vaginal birth only in 2010-2011 (Mann Whitney U test).

§OR of OASIS adjusted for maternal age, gestational age, prior caesarean section, birth weight, mode of delivery, episiotomy, epidural analgesia and maternal smoking associated with OASIS. aOR, adjusted OR; uOR, unadjusted OR. 


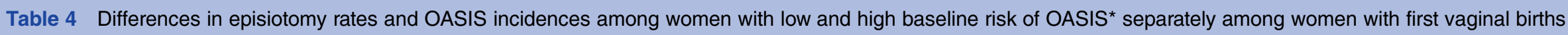
including women admitted for first vaginal birth after a prior caesarean section and among women with at least one prior birth women between four 2 -year time period in 2004-2011 in Finland

\begin{tabular}{|c|c|c|c|c|c|c|}
\hline Characteristic & 2004-2005 & 2006-2007 & 2008-2009 & 2010-2011 & p Value & Pooled 2004-2011 \\
\hline \multicolumn{7}{|l|}{ Women with first vaginal birth } \\
\hline $\mathrm{n}$ & 40995 & 41664 & 42684 & 42738 & & 168081 \\
\hline \multicolumn{7}{|l|}{ Distribution of risk groups* } \\
\hline Low risk (\%) & 72.3 & 71.6 & 71.6 & 71.1 & 0.002 & 71.6 \\
\hline High risk (\%) & 27.7 & 28.4 & 28.4 & 28.9 & & 28.4 \\
\hline \multicolumn{7}{|l|}{ Low risk, risk scores $<1.85$} \\
\hline Episiotomy use (\%) & 50.4 & 47.4 & 41.9 & 36.9 & $\leq 0.001$ & 44.1 \\
\hline Change in episiotomy use (uOR, $95 \% \mathrm{Cl}$ ) & 1 (reference) & $0.88(0.86$ to 0.91$)$ & 0.71 (0.69 to 0.73$)$ & 0.58 (0.56 to 0.60$)$ & & \\
\hline OASIS $(\%(n))$ & $0.8(242)$ & $1.1(336)$ & $1.1(348)$ & $1.3(396)$ & $\leq 0.001$ & $(1322)$ \\
\hline OASIS with episiotomy (\% (n)) & $0.7(111)$ & $1.3(189)$ & $1.6(210)$ & $2.1(236)$ & & $1.4(746)$ \\
\hline OASIS without episiotomy (\% (n)) & $0.9(131)$ & $0.9(147)$ & $0.8(138)$ & $0.8(160)$ & & $0.9(576)$ \\
\hline Change in OASIS (UOR, 95\% CI) & 1 (reference) & $1.38(1.17$ to 1.63$)$ & $1.40(1.19$ to 1.65$)$ & $1.60(1.37$ to 1.88$)$ & & \\
\hline \multicolumn{7}{|l|}{ High risk, risk scores $>1.85$} \\
\hline Episiotomy use (\%) & 72.8 & 72.7 & 71.5 & 66.6 & $\leq 0.001$ & 70.8 \\
\hline Change in episiotomy use (uOR, $95 \% \mathrm{Cl}$ ) & 1 (reference) & 0.99 (0.94 to 1.05$)$ & 0.94 (0.88 to 0.99$)$ & 0.74 (0.70 to 0.79$)$ & & \\
\hline OASIS (\% (n)) & $2.6(297)$ & $2.6(309)$ & $2.6(311)$ & $2.7(336)$ & 0.89 & $2.6(1253)$ \\
\hline OASIS with episiotomy (\% (n)) & $2.4(201)$ & $2.7(230)$ & $2.7(237)$ & $3.0(249)$ & & $2.7(917)$ \\
\hline OASIS without episiotomy $(\%(n))$ & $3.1(96)$ & $2.4(79)$ & $2.1(74)$ & $2.1(87)$ & & $2.4(336)$ \\
\hline Change in OASIS (uOR, 95\% CI) & 1 (reference) & $1.00(0.85$ to 1.17$)$ & $0.98(0.83$ to 1.15$)$ & 1.04 (0.89 to 1.22$)$ & & \\
\hline \multicolumn{7}{|l|}{ Women with at least one prior vaginal birth } \\
\hline $\mathrm{n}$ & 52274 & 53338 & 55180 & 55765 & & 216557 \\
\hline \multicolumn{7}{|l|}{ Distribution of risk groups* } \\
\hline Low risk (\%) & 75.2 & 76.2 & 77.2 & 76.7 & $\leq 0.001$ & 76.4 \\
\hline High risk (\%) & 24.8 & 23.8 & 22.8 & 23.3 & & 23.6 \\
\hline \multicolumn{7}{|l|}{ Low risk, risk scores $<2.50$} \\
\hline Episiotomy use (\%) & 8.4 & 6.9 & 5.3 & 4.0 & $\leq 0.001$ & 6.1 \\
\hline Change in episiotomy use (uOR, $95 \% \mathrm{Cl}$ ) & 1 (reference) & $0.80(0.76$ to 0.84$)$ & $0.60(0.57$ to 0.64$)$ & 0.45 (0.43 to 0.48$)$ & & \\
\hline OASIS (\% (n)) & $0.1(34)$ & $0.1(59)$ & $0.2(68)$ & $0.2(83)$ & 0.001 & $0.1(244)$ \\
\hline OASIS with episiotomy (\% (n)) & $0.2(7)$ & $0.9(26)$ & $1.2(26)$ & $1.5(25)$ & & $0.8(84)$ \\
\hline OASIS without episiotomy (\% (n)) & $0.1(27)$ & $0.1(33)$ & $0.1(42)$ & $0.1(58)$ & & $0.1(160)$ \\
\hline Change in OASIS (uOR, $95 \% \mathrm{CI}$ ) & 1 (reference) & $1.68(1.10$ to 2.56$)$ & 1.85 (1.22 to 2.79$)$ & 2.24 (1.51 to 3.35$)$ & & \\
\hline \multicolumn{7}{|l|}{ High risk, risk scores $>2.50$} \\
\hline Episiotomy use (\%) & 15.0 & 13.4 & 11.6 & 9.6 & $\leq 0.001$ & 12.4 \\
\hline Change in episiotomy use (uOR, $95 \% \mathrm{Cl}$ ) & 1 (reference) & $0.88(0.82$ to 0.94$)$ & 0.75 (0.69 to 0.80$)$ & 0.60 (0.56 to 0.65$)$ & & \\
\hline OASIS $(\%(n))$ & $0.3(45)$ & $0.5(64)$ & $0.5(58)$ & $0.6(76)$ & 0.04 & $0.5(243)$ \\
\hline OASIS with episiotomy (\% (n)) & $0.5(10)$ & $1.6(27)$ & $1.4(20)$ & $2.9(36)$ & & $1.5(93)$ \\
\hline OASIS without episiotomy $(\%(n))$ & $0.3(35)$ & $0.3(37)$ & $0.3(38)$ & $0.3(40)$ & & $0.3(150)$ \\
\hline Change in OASIS (uOR, $95 \% \mathrm{CI})$ & 1 (reference) & $1.46(0.99$ to 2.14$)$ & $1.33(0.90$ to 1.96$)$ & $1.69(1.17$ to 2.45$)$ & & \\
\hline
\end{tabular}

$\chi^{2}$-test or logistic regression analyses.

${ }^{*}$ The best thresholds to maximise sensitivity and specificity; 1.85 (sensitivity $49 \%$ and specificity $72 \%$ ) in women with first vaginal births including women admitted for first vaginal birth after a prior caesarean section and 2.50 (sensitivity $50 \%$ and specificity $76 \%$ ) and in women with at least one prior birth.

uOR, unadjusted OR. 
Despite the positive associations between episiotomy and OASIS, the likely confounding by indication, our results suggest that episiotomy still had a protective role since women with episiotomy were complicated by OASIS with higher mean risk scores than women without episiotomy as shown in table 3. However, it appeared that mean risk scores among women with OASIS and with episiotomy decreased over time suggesting that along with the policy change in episiotomy use the technique became less protective also among high-risk women. Other data have suggested that narrow-angled episiotomy increases the risk of OASIS and measures such as point of incision, episiotomy length and depth might reduce the OASIS risk. ${ }^{14}$ However, due to observational study design we were able to reveal only associations between the role of episiotomy and OASIS, and therefore well-designed randomised controlled trials of restrictive versus routine lateral episiotomy among high-risk women are still needed.

The most important strength of this study was that the data covered the total population of women with vaginal births over an 8-year period in Finland. Differences in registration routines might have affected OASIS incidences, but both national registers used for this study have extensively validated data quality. ${ }^{515} 16$ The possible limitation was that we were not able to include all known risk factors for OASIS in the models, including the prolonged second stage of birth and abnormal presentation. Furthermore, the data also lack information on all possible indications for episiotomy, including fetal distress, slow crowning and condition of the perineum at birth that might have biased our results. The study results are likely generalisable only to lateral episiotomy.

\section{CONCLUSIONS}

Using an 8-year population-based data we showed that the highest risk of OASIS was associated with high birth weight with vacuum-assisted birth regardless of number of prior vaginal births but the incidences of OASIS were in the order of sevenfold after the first vaginal birth compared to subsequent vaginal births. The observed association between lateral episiotomy and OASIS, was profoundly modified by episiotomy rate, serving here as a surrogate for unmeasured confounding by indication. ${ }^{17}$ Variation in episiotomy rate must contribute to the heterogeneity in previous estimates of this association, both between observational studies in different countries with different episiotomy policies, and studies within the same countries over time. Randomised trials are required to assess the optimal rate of lateral episiotomy for women at high risk of OASIS.

\footnotetext{
Author affiliations

${ }^{1}$ Department of Obstetrics and Gynaecology, Kuopio University Hospital, Kuopio, Finland

${ }^{2}$ Department of Epidemiology and Biostatistics, Imperial College London, London, UK

${ }^{3}$ National Institute for Health and Welfare (THL), Helsinki, Finland

${ }^{4}$ Nordic School of Public Health, Gothenburg, Sweden
}

${ }^{5}$ Department of Epidemiology, Rollins School of Public Health, Emory

University, Atlanta, Georgia, USA

${ }^{6}$ Department of Obstetrics, Oslo University Hospital, Ullevål

${ }^{7}$ Faculty of Medicine, University of Oslo, Norway

${ }^{8}$ University of Eastern Finland, Kuopio, Finland

Acknowledgements We thank Tuomas Selander, MSc, for drawing the figures.

Contributors All authors participated in designing the study. SR managed the dataset and performed statistical analyses. RC, MG, MRK, KL, MRJ and SH were statistical advisors. All authors contributed to the interpretation of the results, as well as to writing and editing the manuscript.

Funding This research received no specific grant from any funding agency in the public, commercial or not-for-profit sectors.

\section{Competing interests None.}

Ethics approval Permission to use the confidential register data in this study was approved on 10 October 2012 by the National Institute for Health and Welfare (THL) in Finland (Reference number 263/05.05.00/2012).

Provenance and peer review Not commissioned; externally peer reviewed.

Data sharing statement No additional data are available.

Open Access This is an Open Access article distributed in accordance with the Creative Commons Attribution Non Commercial (CC BY-NC 3.0) license, which permits others to distribute, remix, adapt, build upon this work noncommercially, and license their derivative works on different terms, provided the original work is properly cited and the use is non-commercial. See: http:// creativecommons.org/licenses/by-nc/3.0/

\section{REFERENCES}

1. Dudding TC, Vaizey CJ, Kamm MA. Obstetric anal sphincter injury: incidence, risk factors, and management. Ann Surg 2008;247:224-37

2. EURO-PERISTAT Project. EUROPEAN PERINATAL HEALTH REPORT. 2010: http://www.europeristat.com/ (accessed 18 Jun 2013).

3. Handa VL, Danielsen BH, Gilbert WM. Obstetric anal sphincter lacerations. Obstet Gynecol 2001;98:225-30.

4. Frankman EA, Wang L, Bunker $\mathrm{CH}$, et al. Episiotomy in the United States: has anything changed? Am J Obstet Gynecol 2009;200:573. e1-7.

5. Laine K, Gissler M, Pirhonen J. Changing incidence of anal sphincter tears in four Nordic countries through the last decades. Eur J Obstet Gynecol Reprod Biol 2009;146:71-5.

6. Andrews V, Sultan $\mathrm{AH}$, Thakar R, et al. Occult anal sphincter injuries-myth or reality? BJOG 2006;113:195-200.

7. Carroli G, Mignini L. Episiotomy for vaginal birth. Cochrane Database Syst Rev 2009;(1):CD000081.

8. Dandolu V, Chatwani A, Harmanli O, et al. Risk factors for obstetrical anal sphincter lacerations. Int Urogynecol J Pelvic Floor Dysfunct 2005;16:304-7.

9. de Leeuw JW, Struijk PC, Vierhout ME, et al. Risk factors for third degree perineal ruptures during delivery. BJOG 2001;108:383-7.

10. Kalis V, Laine $\mathrm{K}$, de Leeuw J, et al. Classification of episiotomy: towards a standardisation of terminology. BJOG 2012;119:522-6.

11. Raisanen $\mathrm{SH}$, Vehvilainen-Julkunen K, Gissler M, et al. Lateral episiotomy protects primiparous but not multiparous women from obstetric anal sphincter rupture. Acta Obstet Gynecol Scand 2009;88:1365-72.

12. Raisanen $\mathrm{S}$, Vehvilainen-Julkunen $\mathrm{K}$, Gissler M, et al. The increased incidence of obstetric anal sphincter rupture-an emerging trend in Finland. Prev Med 2009;49:535-40.

13. Sultan A. Obstetric perineal injury and anal incontinence. Clin Risk 1999;5:193-6.

14. Stedenfeldt M, Pirhonen J, Blix E, et al. Episiotomy characteristics and risks for obstetric anal sphincter injuries: a case-control study. BJOG 2012;119:724-30.

15. Gissler M, Shelley J. Quality of data on subsequent events in a routine medical birth register. Med Inform Internet Med 2002;27:33-8.

16. Sund R. Quality of the Finnish Hospital Discharge Register: a systematic review. Scand J Public Health 2012;40:505-15.

17. McCandless LC. Meta-analysis of observational studies with unmeasured confounders. Int J Biostat 2012;8. doi:10.2202/ $1557-4679.1350$ 